\title{
Service Robots Usage in Marketing Hospitality in China
}

\author{
Ayse Ersoy ${ }^{1} \&$ Ziqi Cui ${ }^{1}$ \\ ${ }^{1}$ Shannon School of Business, Cape Breton University, Sydney, Nova Scotia, Canada \\ Correspondence: Ayse Ersoy, Shannon School of Business, Cape Breton University, Sydney, Nova Scotia, Canada
}

Received: June 14, 2021 Accepted: September 4, 2021 Online Published: September 13, 2021

doi:10.5430/jbar.v10n2p13 URL: https://doi.org/10.5430/jbar.v10n2p13

\begin{abstract}
Since the coronavirus disease 2019(COVID-19) has had brought severe impact on all aspects of the world. A series of interpersonal distancing methods such as ensuring effective and safe social distancing among people, wearing masks, and traffic lockdown measures are also continuing to take effect to curb the continuing outbreak of the COVID-19 ("Advice for the public on COVID-19", 2020). In response to the globally spread of COVID-19, many advanced technologies in the field of Artificial Intelligence (AI) were applied rapidly and played an essential role in the operation for several months. There are many different leading technology categories in the field of artificial intelligence and many different sub-categories within each main technology categories. Moreover, since the AGI technology does not yet reach the basic human intelligence level, this study will focus on the impact of service robots, which are already widely used in the NAI application category, on hospitality marketing in the current situation in China. In this paper the aim is to assess the effectiveness of use of service robots in Marketing Hospitality Industry during the pandemic through a quantitative study.
\end{abstract}

Keywords: Artificial intelligence, marketing hospitality industry, AGI Technology

\section{Introduction}

Since the coronavirus disease 2019 (COVID-19) has had brought severe impact on all aspects of the world. A series of interpersonal distancing methods such as ensuring effective and safe social distancing among people, wearing masks, and traffic lockdown measures are also continuing to take effect to curb the continuing outbreak of the COVID-19 ("Advice for the public on COVID-19", 2020). However, these methods have also caused severe problems for industries that rely heavily on interpersonal interaction (Hoque et al., 2020). According to the data published by the World Health Organisation, as of 27 November 2020, there have been more than 60 million confirmed cases of COVID-19 worldwide, including more than one million deaths. And the number of new cases reported is still showing an increasing trend ("WHO COVID-19", 2020).

In response to the globally spread of COVID-19, many advanced technologies in the field of Artificial Intelligence (AI) were applied rapidly and played an essential role in the operation for several months. It was also the extremely infectious nature of the COVID-19 that has forced service industries that rely on traditional human labour, such as the hospitality industry, to look for ways to reduce human interaction in their services to sustain operations during the epidemic. The use of service robots is one such way, and new ways of using robots have been developed in the process. Examples include disinfection robots for surface disinfection, monitoring robots to assist in medical data monitoring, transport robots to deliver daily supplies and application robots such as drones to provide overhead-view monitoring for an area, all of which are widely recognised technologies (Yang et al., 2020). Also, concerns about the ability of COVID-19 to spread through food had led to more trust in robotic chef restaurants such as the Hema Restaurant in the food preparation sector (Meisenzahl, 2020). Scholars have speculated that the acceptance and trust in high-tech services by people living in China has remarkably increased during the epidemic of COVID-19 (Zeng et al., 2020). The traditional hospitality industry is highly dependent on manual labour and human interaction, which makes labour-related costs consistently important human resources core issue. And for hotel operational reasons, the service robots are considered to increase efficiency and reduce costs. In contrast, for the customers, the use of service robots virtually ensures a safe social distance for them (Ivanov et al., 2020).

In China, where the COVID-19 related situations are mostly under control, the prevention and control of the epidemic have become normalised. Nonetheless, previous research has been conducted on the acceptance of service robots and their impact on consumer propensity; there is a lack of research on the post-epidemic impact. This paper 
examines consumer attitudes towards the application of service robots in the hospitality industry in the post-epidemic in China and whether the use of service robots in hotels impacts consumer propensity to consume. Thus, to explore the marketing potential of service robots application in the hospitality industry in China.

\subsection{Literature Review}

\subsubsection{Artificial Intelligence and Robots}

Firstly, AI is defined in a variety of ways in different directions, and the core of AI is considered to be the ability to imitate intelligent human behaviour or to perform tasks that previously required human intelligence; According to this definition, AI can be divided as Artificial General Intelligence (AGI) and Narrow Artificial Intelligence (NAI) (Patrick, 2020).

AGI is commonly thought of a machine as capable of independent thought and does not require human intervention. In contrast, NAI is typically referred to as a machine that can make autonomous decisions within certain conditions and limits (Goertzel, 2015). In the case of NAI, if conditions and circumstance change, additional human intervention is often required to keep the system functioning correctly, unlike AGI, which can learn and apply existing information as autonomously as humans do (Goertzel, 2014).

As far as robots are concerned, intelligent robots under the AGI classification are still out of reach. Many specially designed unique algorithms have also failed to achieve the fast, intuitive and appropriate behaviour that is common to live creatures (Adami, 2015).

However, there are already many examples of applications for service robots in the field of NAI. One of the well-known service robots in this field has been in operation in China for many years; the Xiaotu robot project in China, which started in 2009, can serve guests as librarians at a later stage. The function of the Xiaotu robot includes interacting in Chinese, give professional answers to domain-specific questions, carry out book searches and interact with other systems (Yao et al., 2015).

There are many different leading technology categories in the field of artificial intelligence and many different sub-categories within each main technology categories. Moreover, since the AGI technology does not yet reach the basic human intelligence level, this study will focus on the impact of service robots, which are already widely used in the NAI application category, on hospitality marketing in the current situation in China.

\subsection{Artificial Intelligence Robots Application}

\subsubsection{Artificial Intelligence Applied in Service}

In the past few years, breakthroughs in the deep learning techniques have led to a significant increase in the accuracy of object recognition (CACM, 2017). It was also based on technological breakthroughs that in 2015 scientists set out a vision of putting robots into the service industry to improve service quality and efficiency and reduce the labour costs (Rodriguez-Lizundia et al., 2015). Simple service robots such as the Pepper social robot are gradually appearing and replacing human employees to serve customers (Pandey \& Gelin, 2018). The constant presence of service robots has led to a phenomenon that continues to impact the interaction and consumption concept of people. With further development and use of AI technology, many parts of human life are becoming more automated, and a part of human service work is being transformed (Klotz, 2018).

Many believe that excessive human substitution can have a negative impact. However, Ming-Hui Huang and Roland T. Rust (2018)argue that the substitution of human jobs by AI technology mainly occurs at the task level and that such substitution can free up part of the work effort of the human employees and can also enhance the productivity of the human employees. There is already extensive replacement of unskilled human labours by AI robots in mechanical tasks where the AI technology is more readily available; which is precisely the replacement theory that Ming-Hui Huang and Roland T. Rust advocates for the rational use and sublimation of human intelligence (Huang \& Rust, 2018). For example, in the task of big data analysis, an AI can analyse a patchwork of data, while a human analyst only needs to analyse the results of the data analysis. Similarly, there are many task levels in the service industry that do not require skilled labour, such as goods delivery, lift guidance, telephone reminder service. Service robots can perform these task levels instead of employees; therefore, employees can have more time to perform higher-level tasks and managers can reduce the use of unskilled labour.

\subsubsection{Artificial Intelligence Robots in Hotels}

The development of AI technology has led to much anticipation about the potential if service robots and those working in the hospitality industry also see it as the future (Ruetz, 2016). For industries such as hospitality, high quality of experience in human-robot interaction pond humanistically is considered to be one of the core 
requirements for service robots, and facial recognition of the user and the ability to respond like a human being during the interaction are essential factors in evaluating the quality of human-robot interaction; Moreover, the ability of service robots to work autonomously, or the stability of the underlying systems, such as movement, positioning and interacting with other systems, is the basis for effective human-robot interaction (Lisetti \& Schiano, 2000). Because of these performance requirements, past attempts to use hotel service robots have not turned out well. Moreover, despite its promise, service robots are still emerging things for thought relative to the long history of the hotel industry, and the debate over the merits of human-robot versus human-human interaction has been ongoing (Tung \& Au, 2018). The first hotel to use robots to replace manual labour was the Henn Na Hotel in Nagasaki, Japan, where service robots worked to perform basic tasks such as luggage handling and room cleaning, but later failed due to unsatisfied perform, resulting in a poor customer experience (Bhimasta \& Kuo, 2019).

Service robots are not usually able to provide the same level of emotional experience as human employees. Still, at the time of Henn Na hotel operation, the technical standards of the service robots were not yet able to meet the everyday needs of the customers. The use of English resulted in a language barrier in communicating with many of the guests, which brought a severe negative impact on the guest experience and forced the Henn Na hotel to suspend part of its robotic staff (Reis et al., 2020). However, subsequent research found that the operating expenses of Henn $\mathrm{Na}$ hotel were lower than those of a traditional hotel; also, many customers were coming to the Henn Na hotel because of the service robots (Reis et al., 2020).

Moreover, Tussyadiah (2020) agrees that the application of service robots within service industry is not comparable with the service experience of a human waiter, and there are several potential risks, such as security and privacy issues. The lack of guaranteed service quality and potential downsides are detrimental to the market image of service robots, and much research has been done on the acceptance of service robots (Tussyadiah, 2020). Choi et al. (2019) conducted an experimental investigation into the actual experiences and expectations of human-robot interaction and showed that, in terms of quality of interaction, purely human employees have the best experience, especially when it comes to communicative behaviour. Also, guests prefer to interact with human employees, although the overall experience and expectations did not differ significantly. According to Chan and Tung (2019), service robots are also able to provide the same quality of service as human employees in specific tasks and offer a unique experience. In this aspect, service robots can relieve the burden of manual labour by replacing some of the work of employees and have an exceptional market value different from that of humans in the same industry. Ivanov and Webster (2019) also agree that robots offer a new experience when interacting with customers and that the delivery of information is far more efficient and reliable than with humans; even robots can provide round-the-clock service with same service quality. These features demonstrate the positive benefits of using service robots within the hospitality industry; also, the market potential for service robots is also increasing due to the current consumer trend towards personalisation and customisation.

\subsubsection{The Purchase Intention and Expectations}

Consumer purchase intention has its roots in psychology and is often used in marketing to predict consumer buying behaviour. Although there are many critical indicators and related influences that are actually used to predict consumer behaviour, the purchase intention is still the dominant determinant of consumer behavior (Zhong et al., 2020). With the growth of the Internet user community, the role of the internet in influencing consumer purchase intentions has been widely noted. The information sharing and customer relationship management on internet platforms, such as hotel ratings, are seen to have a broad impact by generating a continuum of empathic responses (Shang et al., 2017). Research related to consumer purchase intentions is common in the hospitality industry. Due to the fierce competition in the hotel industry, factors that can influence consumer intentions such as the online platform promotion, hotel room quality, hotel decoration style, and hotel atmosphere are a popular research area (Li et al., 2015).

In addition to the use of the internet, the hospitality industry is also expected to see continued technological innovation. However, several years after the advent of robots hotel in Japan, there is still little research into the impact of using the service robots as a marketing factor in the hospitality industry on consumer purchase propensity (Zhong et al., 2020). Besides, research on the impact of robots providing services in hotels on consumer behaviour has focused on user acceptance, and the related technology acceptance model is one of the models commonly used to study this area (Ivanov \& Webster, 2019). However, studies on the impact of online platforms such as Facebook on consumer purchase intentions have found that user expectations are one of the most critical factors influencing consumer behaviour; Negative reviews on websites can negatively impact users' consumption intentions (Dehghani \& Tumer, 2015). 
Apart from the impact of robots in hotels on human resource management, ethics and room quality, only a few researchers have studied the impact of robots on consumer purchase intentions in the hospitality industry, and all predate the COVID-19 pandemic (Zhong et al., 2020).

\subsection{Problem Statement}

In the absence of specific drugs and vaccines, the COVID-19 epidemic has become one of the common externalities in the market. Xie (2020) argues that the longer an outbreak of an infectious disease lasts, the more far-reaching the indirect effects on the market and the more difficult it is to repair. However, the direct impact on the industry caused by an outbreak is more concentrated than an economic crisis and therefore, the repair time will be short. As one of the sectors that better reflects current consumer confidence, tourism is a good indicator of the market's recovery. During the SARS and COVID-19 periods, China's epidemic was quickly brought under control, and the government is gradually opening up markets and stimulating economic recovery. However, even with the help of government policies, some tourism-related businesses went bankrupt in the latter stages of the epidemic. Therefore, the correspondence between market recovery time and the survival time of capital flows for workers is a central issue in transcending market strategies.

It is also true that the hotel industry in China has been hit hard by social distancing measures and closures such as the travel ban imposed in response to the COVID-19 outbreak. Despite a significant recovery in February-March, only 30.05 per cent of hotels returned to over half of their outlets due to the continued cold market, while only 5.91 per cent of hotels were able to return to 80 per cent occupancy in March (China Hospitality Association, 2020).

Moreover, according to the report published in March of the same year by the China Hospitality Association(2020), the Chinese hotel industry is experiencing a severe decline in revenue, surging pressure on operating costs and supply chain pressures; only $3 \%$ of hotels have not laid off staff. Also, the COVID-19 pandemic has radically changed the consumption behaviour, the level of cleanliness and disinfection in hotels will be an essential factor, and there will be a necessary increase in disinfection costs in order to protect customer confidence and sense of security (Assaf \& Scuderi, 2020).

Furthermore, according to Hao et al. (2020), the recovery of China's domestic hotel industry is still influenced by the global market, and there is no possibility of retaliatory growth at a later stage, which means a limited market and a more stimulating market competition.

In the face of such a challenging market environment, it is only by determining the size of the market and actively expanding sales while controlling costs that the hotel can find new areas of consumption growth and then survive. Moreover, as Hao et al. (2020) state, since COVID-19 has fundamentally changed the economic environment for the hotel industry in China and the Chinese tourism market was the first to start recovering, the study of the hotel industry in China will also inspire hotels in other parts of the world in this regard.

\subsection{The Needs of Using Service Robots in Hotels in China}

AI service robots have gained a foothold in the hospitality industry, and in some hotels, they are used to promote products and services to customers; however, this can only be experienced if the customer stays in the hotel. The rise of service robots has been accompanied by research into the purchase intention of consumer, which is now one of the most critical indicators of marketing. Due to the promise of AI robots in the service industry, a recent experimental study launched by Zhong (2020) on the marketing impact of hospitality using service robots to serve consumers has shown that there is a positive impact on consumer willingness to spend and that there is definite practical value in using service robots for marketing.

Furthermore, with COVID-19 in vogue, service robots are accelerating the hospitality industry as demand hits, meaning more automatic equipment and completely contactless service processes.

During the outbreak of COVID-19, the hotel industry in China responded to the government's call for maintaining social distancing measures, and in the subsequent market recovery, non-contact services were widely adopted to boost consumer confidence. For example, Qunar.com has launched the "Stay with confidence" project, which has over 100,000 hotels offering autonomous check-in and robotic room service; Also, the widespread use of similar robotic services has, to some extent, influenced consumers' initial expectations when choosing a hotel( $\mathrm{Li}, 2020)$.

Moreover, as Chan and Tung (2019) point out, the artificial intelligence service robots represent a new service concept, an innovative form of service that can directly enhance a hotel's core competitiveness. Also, consumers become highly sensitive to human interaction due to the health crisis; more contactless service means a higher level of customer trust (Jiang \& Wen, 2020). From this perspective, the collaboration between service robots and staff will 
undoubtedly be a very attractive selling point for a long time.

\subsection{Research Question}

Firstly, there is a limited number of research on the impact of robot services on consumer purchase intentions in the hospitality industry. Most of the existing research predates the COVID-19 pandemic or has not considered the impact of COVID-19. However, it is undeniable that the pandemic of COVID-19 has had an enormous shock on consumer behaviour, and in this context, the actual impact of robot services on consumer intentions in the hospitality industry is in a relative limbo.

Besides, given the relatively abundant existing research on the acceptance of robots in the hospitality industry, this study will emphasise the impact of robotic applications in the hospitality industry in China on purchase intentions during COVID-19 pandemic. Furthermore, consumer expectations will be assumed to be the second research factor to predict the potential marketing value of using robots in China's hospitality industry.

The research questions are:

1) Is there a relationship between consumer purchase intention and the use of robots in the Chinese hospitality industry during the pandemic of COVID-19?

2) Will the consumer purchase intention in choosing hotels continue to be impacted by the use of service robots post the pandemic?

3) Are the existing hotels in China that already use robots able to meet consumers' expectations?

By answering these research questions, this study hopes to understand the actual market impact of the adoption of service robots in the Chinese hospitality industry during an epidemic and provide relevant support for further investigations in related areas.

\subsection{Relevance and Importance of the Research}

Firstly, the impact of the COVID-19 epidemic on consumer confidence has been enormous, and a high-quality evolve of the hospitality industry is an essential part of rebuilding consumer confidence. There is a gap in the cultivation of high-quality labour; meanwhile, the market freeze has caused Chinese hotel companies to face financial problems (Chen et al., 2020). Considering the advantages and development status of AI robots, the adoption of service robots in hotels to replace manual labour can effectively fill the gap in talent cultivation and reduce some of the human costs.

The hotel industry in China today has been using robots to replace some of the manual labour long before the COVID-19, and the increased demand for contactless service due to the impact of COVID-19 has further expanded the demand for service robots. The Huazhu Hotel Group alone has nearly 6,000 hotels with robotic services in 2020 (Mi, 2020).

Due to the nature of AI applications, a great portion of the existing research on service robots has focused on human-robot interaction, while market research related to the hospitality industry has focused more on the direction of customer acceptance of service robots. While authoritative reports acknowledge the direction of the hotel industry structure towards digital intelligence application, there is still a lack of recent research on the actual impact of digital intelligence application on consumers (Chen et al., 2020).

This study will add to the current gap in the impact of service robots on consumer purchase intention, and will enable an assessment of whether the robotic services now being implemented are meeting consumer needs and expectations, providing data to inform the next step towards digital intelligence application in Chinese hotels. At the same time, although not applicable to the international market, research on the impact of service robots on consumer preferences in the Chinese market can still provide reference for research on the hospitality industry in the international context.

\section{Research Methodology}

This study will investigate whether the use of service robots in the hospitality industry is positively appealing to consumers in China today. Considering the impact of COVID-19 on the market, consumer behaviour may have changed permanently, and consumer confidence has become one of the critical factors in achieving industry recovery and business growth. Therefore, investigating the level of service that existing service robots can provide and whether the consumer experience they deliver can meet consumers' expectations is also one of the core topics of this study. Secondly, price, as one of the significant market factors, has a considerable impact on consumer purchase behaviour and purchase psychology; therefore, in this study, the investigation related to price on whether consumers choose hotels with service robots is also one of the necessary topics to study the market potential of service robots. In 
addition, the tourism industry in China has begun to recover, and more consumers are expected to enter the market than during the epidemic. A survey about purchase propensity of consumers who have experienced robotic services, in addition to those who have not, can provide some indication of how consumer expectations have changed since the epidemic.

By completing the topics of consumer purchase expectations and the influence of price on consumer propensity, this study hopes to answer how the practical application of service robots in the hospitality industry will affect consumer purchase intentions in the post-COVID-19 Chinese market. It is also hoped that this study will provide an overview of the market outlook for the use of service robots in the Chinese hospitality industry and pave the way for subsequent research across industries and geographic markets.

\subsection{Hypotheses}

Based on similar previous studies, the use of service robots in hotels should still have some market appeal at the moment. And given the impact of COVID-19 and the positive role of service robots in other industry sectors during the epidemic, the findings of this study should reflect a high rate of consumer acceptance and willingness to purchase.

As to the issue of meeting consumer expectations, existing service robots working in hotels should not be able to meet the expectations of most consumers. However, the positive impact of service robots on consumer propensity is still expected to outweigh the negative impact of a deteriorating price factor. In the survey results, it is expected that the loss of consumers from higher prices will remain a small percentage. In particular, the group of consumers who have not experienced service robots is expected to show a higher desire to purchase, and the proportion of those who are willing to try will be less influenced by price factors than the group of consumers who have experienced the service robots before. For consumers who have experienced service robots, a larger proportion of those with unsatisfactory experiences before should be willing to make a second purchase in the current survey and less influenced by price; In contrast, the vast majority of those with satisfactory experiences are expected to be willing to make a second purchase and less influenced by price. Both experienced and inexperienced consumers are expected to have a higher propensity to consume and be less influenced by price, even if consumer expectations are not met. Combined with the analysis of the current state of the Chinese hotel industry, the findings of this study should show a positive trend of correlation between service robot applications and purchase intention.

\subsection{Research Method}

This study focuses on quantitative research to uncover the relationship between the use of service robots in China's hospitality industry and consumer choice preferences. Moreover, this study will mainly adopt a questionnaire research method combined with an experiment to test whether the existing service robots in China can meet Chinese consumers' consumer expectations. The questionnaire will be administered on a Chinese questionnaire website. Basic information about the study, the use of the data, the relevant research institution and the relevant contact details of the researcher will be provided before the questionnaire begins. The questionnaire will be entirely anonymous, with no personally identifiable information collected from participants, who will be able to change, withdraw and request deleting their responses within one week after submitting the questionnaire.

The questionnaires will mainly be Likert Scale type of answers, dividing participants' responses into five different rating scales: Strongly Agree, Agree, Neutral, Disagree and Strongly Disagree in that order. This allows for a more accurate quantitative analysis of consumer tendencies and expectations. The experimental part of the questionnaire was to ask the participants to watch the video or pictures of the service robot work in a hotel provided within questionnaire after the questionnaire part one and to answer the second part of the questionnaire after the viewing. Some of the questions in the second part of the questionnaire will be essentially the same as some of the first part questions related to purchasing intentions. The answers to the relevant questions from before and after viewing the service robot information will analyse whether existing service robots can meet consumer expectations. The actual market potential for service robots can be analysed by examining the change in the propensity of participants to consume before and after the experiment.

Since the user group is comprehensive and that factors such as age, gender and occupation have a considerable influence on the survey results, the questionnaire for this study will exclude the influence of such factors. It will only be analysed in groups based on whether the participants have a short-term travel need and whether they have stayed in a hotel with a service robot. As prices have a strong influence on consumer purchase intention and expectations, the impact of price changes will also be included in a dedicated question. The impact of price reductions will also be included across the board, regardless of subgroup, considering that some consumers have a "you get what you pay 
for" consumer mindset.

\subsection{Research Design}

Since the quantitative analysis was used to generalize the variable of purchase intention and service quality of hotels using service robots in China today, this study will focus on a causal-comparative research design, with the questionnaire section dividing participants into two groups based on the variable of whether or not they have ever stayed in a hotel with a robot. Throughout the experiment, viewing image data of real service robots serving in Chinese hotels today was used as the independent variable, with participants' responses before viewing as the control group and responses after viewing as the experimental group, thus allowing for comparative analysis and minimising the influence of empirical factors on the results. As the price was one of the important variables affecting the results, the questionnaire analysed price as a particular variable across all participants, thus excluding price expectations. The second part of the experiment only adds uniformly standardised information to test whether the purchase intention is consistent before and after the addition of the variables and to analyse whether consumption expectations are met by the quality of the services presented in the material. Also, as the questions accepted by the same group did not relate to factors such as brand and hotel facilities, and the price factor was analysed separately, influencing factors such as brand perception and reputation were eliminated as far as possible. Simultaneously, the questions were set to minimise the potential for questionnaire questions to induce participants. As this study attempts to assess whether consumers' initial expectations are met, no particular factors that impact expectations are added to the experiment, such as restrictions on the hypothetical price range.

The experimental method was chosen mainly because controlling for variables and excluding some of the influencing factors ensures an accurate causality analysis. Although no replication of the experimental study was conducted to increase the reliability of the data, this experimental design can still be considered a viable method for testing the causality of the content of this study. Reference to the research methods used by scholars in the hotel field, such as the effect of hotel reviews on purchase intention (Tsao et al., 2015) and the effect of picture information on purchase intention (Leung et al., 2017), would suggest that an experimental approach would be more valid for this study.

\subsection{Instrumentation}

Given the broad, complex and random nature of the potential participant group, this questionnaire will outline the purpose of the survey, data use, privacy protection and other information before the questionnaire begins; with consent confirmation that only those who consent will be able to continue to participate in the questionnaire and can withdraw at any time during the experiment and within one week of its completion. Besides, given the lack of relevant expert models at this stage, the questionnaire was used to screen and group the participants through the fixed alternative questions, and the Likert scale questions were used to assess the participants' perceptions.

Given the time taken to collect the questionnaire responses, the purpose of the study, and the suitability of data analysis software, no open-ended questions will be designed in this questionnaire. All responses will only be collected if the confirmation of the consent form has been completed and the questionnaire has been fully completed. The questionnaire responses that do not meet the criteria are only recorded or are treated as missing data at the analysis stage. The questionnaire will be reviewed and changed by expert consultants in the field of marketing to determine the feasibility of the content before it is officially launched.

Considering Yunji Technology's leading market share and extensive robot coverage, the hotel robot service process demonstrated in this questionnaire will be selected to showcase Yunji Technology's hotel service robots.

\subsection{Sampling}

Given the impact of COVID-19 and the complexity and breadth of the actual consumer group in the hospitality industry, this study will be completed through a reputable questionnaire website in China. Moreover, the questionnaire will be used to find random participants through online promotions of the questionnaire link and offline diffusion of the questionnaire link. As the experimental design does not group participants in the control and experimental groups; As the questionnaire content does not address individual differences such as brand, it ensures that individual differences in the same group (Experienced or inexperienced) do not influence the results.

The information viewing between the first and second part of the questionnaire will be set as a mandatory viewing, and only participants who have completed the information viewing will be able to fill in the second part of the questionnaire, which will ensure the credibility of the final sample. Questions with causal coherence were also set in the specific questionnaire, enabling an assessment of the reliability of the sample by comparing before and after answers to relevant questions from the same participants. For example, if a participant answers that he or she has had 
a satisfactory experience and then gives a large number of negative comments in the following experience assessment question, or gives a negative answer in the following question on whether the individual needs are met, this participant can be excluded from the data. Also, considering that the user group is not only Chinese speakers; thus, the questionnaire will be conducted in both English and Chinese to avoid wrongly narrowing down the user group.

Specifically, eight Likert scale questions were designed for each group in the first part of the questionnaire, covering the service experience of the service robot (Four questions), the impact of the robot service on price expectations (One question), the purchase intention without the influence of price (One question), the reduction of risk of disease transmission by the robot service (One question), and the ability of the robot service to meet consumer needs (One question). The second part of the questionnaire, on the other hand, was structured similarly to the first part, with the questions focusing on the service robots presented in the image data rather than on the participants' initial expectations. An additional open-ended question was created at the end of the questionnaire to collect relevant perceptions of service robots from valid participants.

\subsection{Data Analysis}

Before starting the analysis, the data obtained will first be tested for the reliability of the Cronbach's coefficient using SPSS software to ensure the internal consistency of the overall sample data and the credibility of the data.

The data will be analysed using Statistical Package for the Social Sciences (SPSS) software to perform a functional analysis of the data to find the functional relationship equation. Therefore, to determine whether the data derived from the Likert scale questions in the pre-and post-experimental studies are statistically causal. In the scenario, the propensity to consume is set as a coefficient $\mathrm{Y}$, the variables are consumption expectation satisfaction $\left(\mathrm{X}_{1}\right)$ and price $\left(\mathrm{X}_{2}\right)$, and the coefficients of influence of the relevant factors are $\mathrm{a}$ and $\mathrm{b}$. If the results are linear, the functional equation is:

$\mathrm{Y}=\mathrm{aX} \mathrm{X}_{1}+\mathrm{bX}_{2}+$ error

If the result is an exponential relationship, the functional equation is

$\log Y=a \log X_{1}+b \log X_{2}+$ error

To verify the validity of the statistical function and the expected large sample size, the F-Statistic will be used to solve the ratio of between-group variability and within-group variability through the ANOVA method. Furthermore, the P-value will be compared with the statistic confidence level through computer software.

Statistical theory suggests that the value of reducing error by increasing the sample size is normally distributed, so that there are maximum and minimum values corresponding to the error value for increasing and decreasing sample size, and that changes in sample size within a given range have little effect on the error value ("Sample Size and Margin of Error", 2021). Given the expected sample size for this study, the expected statistic confidence level for this study is approximately $95 \%$. Therefore, when the p-value is less than or equal to $5 \%$, then these data analysis results are valid; otherwise, the results are invalid.

In this study, the answers to the Likert scale questions are ordered variables, which are assigned a value of 1-5 and are considered as fixed distance variables, and the Mantel-Haenszel trend test will be used to verify the autocorrelation of, variables $X_{1}$ and $X_{2}$. When the results pass autocorrelation verification, the Best Linear Unbiased Estimators(BLUE) test is continued to verify that it is the best function. Otherwise, the function will be corrected. As there are multiple sets of data to be validated before and after the experiment, the statistical analysis process may involve multiple modelling analyses depending on the actual situation.

In addition to the causal analysis of the data, a funnel analysis of the data will be conducted to attempt to analyse changes in purchase intention of participants and their conversion rates, facilitating analysis of the actual portion of affected purchase intention.

\section{Research Results}

The questionnaire was divided into two versions, Chinese and English, for response collection, of which 681 people participated in the Chinese version, 572 completed the questionnaire (25 refused to participate), and 109 did not complete it (Appendix 1). The English version of the questionnaire had not received any response by the closing date. Therefore, the data for the subsequent data analysis section was only used the data collected from the results of the Chinese version of the questionnaire.

Specifically, $95.99 \%$ of participants in this collection regularly stayed in hotels before the outbreak, and $94.49 \%$ had 
plans to stay in hotels in the next year or two (Appendix 2); This is partly a reflection of the current recovery in consumer confidence in mainland China, where the market for the hotel industry has begun to recover rapidly. The decline in travel numbers due to the epidemic will rebound in the future, and this current vacancy will be a hugely competitive and growth area for the hotel industry in the future.

Of all valid participants, $91.95 \%$ had experienced the services provided by a service robot in a hotel, with only $2.64 \%$ of them expressing dissatisfaction with their experience (Appendix 3); This can suggest that service robots have been able to meet the consumer expectations of most consumers in the past, which provides more positive support for the questions in this study. However, comparisons lack the influencing factor of the epidemic, but to a certain extent, it reflects the current consumer tendencies in the hotel market.

In the follow-up Likert scale questions for experienced consumers, more than $50 \%$ rated the robot service positively (Strongly Agree, Agree), and less than 20\% rated it negatively (Disagree, Strongly Disagree) (Appendix 4). The questions focused on five areas: efficiency, interaction, quality of service, service experience, and hotel price. The majority of participants who experienced the robot service was satisfied with the robot and remained positive on the hotel price question.

Among consumers who had not experienced a robot service, $85 \%$ of participants had a positive impression of the service robot (Appendix 5). Unlike those who have experienced it, the positive impressions of these participants represent the consumer expectations of the potential consumer group concerning hospitality service robots. The relationship between consumers' purchase intentions and the use of service robots can be inferred to some extent, but further analysis is needed.

In the follow-up Likert scale question for consumers who had not experienced it, participants' ratings were more divergent, with a polarisation of positive and negative ratings (Appendix 6). The majority of participants gave a neutral rating, while only a small number of participants gave both strongly positive and strongly negative ratings in all five questions. Although potential consumers have some positive impressions of service robots, they do not have a specific idea of their efficiency, interaction, quality of service, service experience, or hotel price. Thus, this is a good marketing opportunity for the hospitality industry. However, the analysis should base on a case-by-case basis, considering the small proportion of people in this segment.

On the other hand, $94.14 \%$ of participants said they would choose to stay in a hotel that offers robot services for future travel (Appendix 7). This question did not differentiate between participants in terms of whether they had experienced a service robot's services, but it still reflects that the use of a service robot influences consumers' purchase intentions. Whether this positive impact will persist requires further analysis.

The responses to questions involving whether service robots reduce disease transmission risk, meet the needs and attractive or not showed positive results. On the question designed for the factor COVID-19 epidemic, 50.5\% of the participants agreed with service robots' contribution to reducing disease transmission risk, while $23.83 \%$ disagreed (Appendix 8). The results can be concluded that the use of service robots still has a positive impact on consumers' purchase intentions after the epidemic. Furthermore, 50.51\% of participants expressed a preference for hotels with service robots compared to hotels with human service (Appendix 8). Without providing a picture to show the robot's service process, it can already be assumed that half of the participants' purchase intentions are positively related to the use of robots and will persist after the epidemic is over. Also, about a quarter of the participants do not receive the influence of using a robot.

After viewing the images of the service process of the service robot, there was no significant change in the proportion of participants who indicated that they would choose to stay in a hotel that offered robot services for future trips (Appendix 9).

In terms of this phenomenon, it is not entirely clear that the existing hotels in China that already use robots can meet consumer expectations. However, it can be argued that the service of the robot showed in the survey, which is now widely used in China, can meet the expectations of most consumers, or that human interaction services are no longer an absolute determinant of consumer choice in the hospitality industry in China.

In the follow-up Likert scale questions, participants generally rated positively the ability to meet demand, attractiveness, safety during an epidemic, and usefulness of the application. For the question on price, the majority of participants also gave positive ratings, and $53.17 \%$ said that the low price did not raise doubts about the quality of the service and the experience of the stay (Appendix 10). Furthermore, this indicates that the service robots adopted by the Chinese hospitality industry can meet consumer expectations but still need to be adjusted to adapt to the future market. As this study does not address the comparison between manual and robotic services, no questions were 
designed. Thus, it can only be assumed that a human-like service experience is still the mainstream expectation.

The final part set of seven questions reflects the positive image that service robots present among the consumer base, with the majority of consumers agreeing with the quality of service provided by service robots and the ability of service robots to provide a safer service during an epidemic. Moreover, $51.53 \%$ of the participants said that the services of the service robots shown in the pictures were attractive, and more than half of the participants said that they would prefer to stay in a hotel with a service robot even if the price was higher than that of a human served hotel (Appendix 10).

Overall, the adoption of service robots in hotels can positively impact consumer purchase intentions. Although this study did not conduct specific in-depth research on the service quality and process of the robots, the results of the responses to the relevant questions still indicate that the self-service provided by service robots, as a mode of interaction distinct from traditional manual hotels, is more attractive to potential customers. Also, it is well placed to strengthen the relationship with existing customers, contributing to expanding a loyal customer base. Besides, the majority of participants acknowledged the efficiency of the service robots, the unique experience, including the price aspect of the hotel. The attitudes of participants differed significantly on the issue of the efficiency of the service robots, and it can be concluded that the ability of the service robots to provide a standardised service of the same quality at all times is a significant attraction for the customer; this is one of the most critical factors that have a significant impact on the customer's purchase intention, in addition to the interactive factor.

It is worth noting that the majority of participants did not agree that the service experience of service robots was superior to that of human service but were still willing to choose hotels with robotic service, reflecting the significant influence of the differential factor of whether or not to adopt a service robot on customer purchase intention.

\subsection{Data Analysis}

Before the correlation analysis of customer satisfaction and the using of hotel robot, it is necessary to make a preliminary analysis of the reliability of the data collected by the questionnaire. In this part, Cronbach's alpha analysis will be used to analyze the options involved in this paper. The results are as follows,

\begin{tabular}{|c|c|c|c|}
\hline \multicolumn{4}{|c|}{ Case Processing Summary } \\
\hline & & $\mathrm{N}$ & $\%$ \\
\hline \multirow[t]{3}{*}{ Cases } & Valid & 449 & 78.5 \\
\hline & Excluded $^{\mathrm{a}}$ & 123 & 21.5 \\
\hline & Total & 572 & 100.0 \\
\hline
\end{tabular}

a. Listwise deletion based on all variables in the procedure.

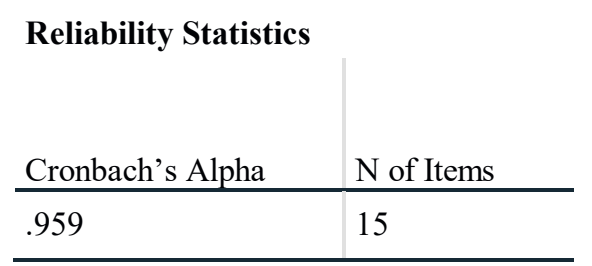

Figure 1.

As shown in the figure, the Cronbach's alpha of the collected questionnaire reaches 0.959 , which indicates that the collected questionnaire has reached an EXCELLENT level. The same investigator has made consistent choices according to his behaviour habits for the tendency choices listed in different topics. In other words, the following analysis can be based on the correct data.

First of all, the first two questions are supposed to make the linear correlation analysis on the first two problems to judge that the epidemic has affected the travel plans of people who often need to travel. 
Table 1.

\section{Correlations}

\begin{tabular}{|c|c|c|c|}
\hline & & $\begin{array}{l}\text { Before COVID-19, do } \\
\text { you often have the } \\
\text { needs of staying at } \\
\text { hotel? }\end{array}$ & $\begin{array}{l}\text { Do you plan to stay in a } \\
\text { hotel (travel plan) in } \\
\text { the near future (within } \\
1-2 \text { years)? }\end{array}$ \\
\hline \multirow{3}{*}{$\begin{array}{l}\text { Before COVID-19, do you often have the } \\
\text { needs of staying at hotel? }\end{array}$} & Pearson Correlation & 1 & .021 \\
\hline & Sig. (2-tailed) & & .628 \\
\hline & $\mathrm{N}$ & 546 & 524 \\
\hline \multirow{3}{*}{$\begin{array}{l}\text { Do you plan to stay in a hotel (travel } \\
\text { plan) in the near future (within } 1-2 \\
\text { years)? }\end{array}$} & Pearson Correlation & 0.21 & 1 \\
\hline & Sig. (2-tailed) & .628 & \\
\hline & $\mathrm{N}$ & 524 & 524 \\
\hline
\end{tabular}

This shows that the correlation is negative, indicating that COVID-19 has indeed become a barrier to people's outbound travel to some extent, but at the same time, the absolute value of correlation is only 0.021 . This shows that the effect is shallow in China, and the epidemic does not interrupt the original intention of people to travel. It can therefore be assumed that the data collected in this study can be extrapolated to future customers in the Chinese hospitality market and that the results of this study on the effect of service robots on purchase intentions are also applicable to predicting the actual market effects of service robots in the Chinese hospitality market in the future. This suggests that service robots are more responsive to customer expectations in terms of interaction. One of the reasons customers choose hotels that employ service robots may be that the human-machine interaction of existing service robots meets their needs and can provide a different experience to human service.

According to the third and fourth questions in the questionnaire, most of the passengers who have experienced the service robot in the hotel have left a good impression on it. Next, go to question 7. This question lists some characteristics of service robots for the respondents. Each characteristic is divided into different levels. The respondents express their recognition of the characteristics of service robots by choosing the level. From the collected data, it can be seen that the respondents do not hold the same degree of recognition for each feature of the service robot. Therefore, a preliminary conclusion can be drawn that the combination of some robot features has a positive impact on passengers.

Table 2.

\begin{tabular}{|c|c|c|c|c|c|c|}
\hline \multicolumn{7}{|l|}{ Correlations } \\
\hline & & $\begin{array}{l}\text { robot service } \\
\text { is fast and } \\
\text { convenient }\end{array}$ & $\begin{array}{l}\text { the } \\
\text { interaction } \\
\text { with the robot } \\
\text { is novel and } \\
\text { interesting }\end{array}$ & $\begin{array}{l}\text { the service } \\
\text { quality of } \\
\text { robot is better } \\
\text { than that of } \\
\text { human }\end{array}$ & $\begin{array}{l}\text { robot's } \\
\text { service } \\
\text { experience is } \\
\text { more } \\
\text { advanced }\end{array}$ & $\begin{array}{l}\text { compared } \\
\text { with } \\
\text { traditional } \\
\text { hotel, the } \\
\text { price of the } \\
\text { hotel using } \\
\text { robot services } \\
\text { is reasonable. }\end{array}$ \\
\hline \multirow{3}{*}{$\begin{array}{l}\text { robot service is fast and } \\
\text { convenient }\end{array}$} & Pearson Correlation & 1 & $.632^{* *}$ & $.505^{* *}$ & $.451^{* *}$ & $.604^{* *}$ \\
\hline & Sig. (2-tailed) & & .000 & .001 & .003 & .000 \\
\hline & $\mathrm{N}$ & 40 & 40 & 40 & 40 & 40 \\
\hline \multirow{3}{*}{$\begin{array}{l}\text { the interaction with the } \\
\text { robot is novel and } \\
\text { interesting }\end{array}$} & Pearson Correlation & $.632^{* *}$ & 1 & .302 & $.515^{* *}$ & $.389^{*}$ \\
\hline & Sig. (2-tailed) & .000 & & .058 & .001 & .013 \\
\hline & $\mathrm{N}$ & 40 & 40 & 40 & 40 & 40 \\
\hline
\end{tabular}




\begin{tabular}{|c|c|c|c|c|c|c|}
\hline the service quality of & Pearson Correlation & $.505^{* *}$ & .302 & 1 & $.352^{*}$ & $.477^{* *}$ \\
\hline robot is better than that & Sig. (2-tailed) & .001 & .058 & & .026 & .002 \\
\hline of human & $\mathrm{N}$ & 40 & 40 & 40 & 40 & 40 \\
\hline service & Pearson Correlation & $.451^{* *}$ & $.515^{* *}$ & $.352^{*}$ & 1 & $.573^{* *}$ \\
\hline experience is more & Sig. (2-tailed) & .003 & .001 & .026 & & .000 \\
\hline advanced & $\mathrm{N}$ & 40 & 40 & 40 & 40 & 40 \\
\hline Compared with & Pearson Correlation & $.604^{* *}$ & $.389^{* *}$ & $.477^{* *}$ & $.573^{* *}$ & 1 \\
\hline $\begin{array}{l}\text { traditional hotel, the } \\
\text { price of the hotel using }\end{array}$ & Sig. (2-tailed) & .000 & .013 & .002 & .000 & \\
\hline $\begin{array}{l}\text { robot services is } \\
\text { reasonable. }\end{array}$ & $\mathrm{N}$ & 40 & 40 & 40 & 40 & 40 \\
\hline
\end{tabular}

**. Correlation is significant at the 0.01 level (2-tailed).

*. Correlation is significant at the 0.05 level (2-tailed).

According to the results of correlation analysis of the characteristics of robots, the two most relevant factors are robot service experience is more advanced and the interaction with the robot is novel and interesting; the interaction with the robot is level and interesting, and compared with traditional hotel, the price of the hotel using robot services is reasonable. It could be illustrated that the interaction of robots is novel and interesting, the service experience of robots is more high-end, and the service provided by robots is more convenient than human services. These interaction factors are the main reasons why people have a good impression of robot services.

The 9th question of the questionnaire reflects a trade-off between the convenience that robots bring to customers and the different prices customers may have to pay from traditional hotels. From this, it could be assumed that the experience that service robots bring to customers can make them pay different prices from traditional hotels. Based on the data obtained from the questionnaire, the next step is to experiment with a linear regression analysis to demonstrate the hypothesis further.

$\mathrm{H}_{0}$ : robots can satisfy most of customers' needs but cannot make them pay different prices from traditional hotels.

$\mathrm{H}_{1}$ : robots can meet most of customers' needs and allow them to pay different prices from traditional hotels.

Table 3.

\begin{tabular}{|c|c|c|c|c|c|c|}
\hline \multicolumn{7}{|c|}{ Coefficients $^{\mathrm{a}}$} \\
\hline \multirow[b]{3}{*}{ Model } & & \multirow{2}{*}{\multicolumn{2}{|c|}{ Unstandardized Coefficients }} & \multirow{3}{*}{$\begin{array}{l}\text { Standardized } \\
\text { Coefficients } \\
\text { Beta }\end{array}$} & \multirow[b]{3}{*}{$\mathrm{t}$} & \multirow[b]{3}{*}{ Sig. } \\
\hline & & & & & & \\
\hline & & $\mathrm{B}$ & Std. Error & & & \\
\hline \multirow[t]{2}{*}{1} & (Constant) & .899 & .098 & & 9.213 & .000 \\
\hline & $\begin{array}{l}\text { service robot can effectively meet } \\
\text { most of your needs in the hotel }\end{array}$ & .692 & .037 & .641 & 18.550 & .000 \\
\hline
\end{tabular}

The results show that the probability value of accepting the original hypothesis is lower than $1 \%$, so the original hypothesis (H0) can be rejected, and the alternative hypothesis (H1) can be accepted. In addition, the linear regression equation of the two factors can be shown by the $\boldsymbol{\beta}$ value listed in the figure.

$Y=0.90+0.69 X$

This equation shows that the degree of service that the service robot can provide is directly proportional to the customer's acceptance of the price. For every 100 units of robot service, 69 people will pay less attention to the price.

As shown in question 36, after showing the photos of the service robots to the respondents, the respondents' supporting position and attitude towards the service robot also changed. 
It can be argued here that service robots can meet most of the needs of consumers, and even when the price is taken into account, it still influences consumers purchase intention. However, current data shows that consumers are not sensitive to price fluctuations associated with adopting service robots in hotels. Moreover, the low sensitivity to price fluctuations is a strong argument favouring the hotel industry to use robots to further reduce labour costs, given that service robots can improve the efficiency of hotel operations and reduce labour costs. However, it also suggests that the influence of price factors on customer purchase intention may be mitigated in the current state of the market. For hotels, price wars are not necessarily an inevitable option following the adoption of robotic services.

Table 4.

\begin{tabular}{|c|c|c|c|c|c|c|c|c|}
\hline \multicolumn{9}{|l|}{ Correlations } \\
\hline & & $\begin{array}{l}\text { if the price of } \\
\text { hotels using } \\
\text { service robots } \\
\text { is slightly } \\
\text { higher than } \\
\text { that of } \\
\text { traditional } \\
\text { artificial } \\
\text { hotels, you } \\
\text { will also } \\
\text { choose hotels } \\
\text { using service } \\
\text { robots. }\end{array}$ & $\begin{array}{l}\text { the } \\
\text { service } \\
\text { robot } \\
\text { shown } \\
\text { in the } \\
\text { picture } \\
\text { can } \\
\text { meet } \\
\text { your } \\
\text { needs. }\end{array}$ & $\begin{array}{l}\text { the service } \\
\text { robot } \\
\text { shown in } \\
\text { the picture } \\
\text { is } \\
\text { attractive } \\
\text { to you. }\end{array}$ & $\begin{array}{l}\text { the service } \\
\text { robot } \\
\text { shown in } \\
\text { the picture } \\
\text { can } \\
\text { provide } \\
\text { safer } \\
\text { service } \\
\text { during the } \\
\text { epidemic } \\
\text { period. }\end{array}$ & $\begin{array}{l}\text { if the price of a } \\
\text { hotel using } \\
\text { service robot is } \\
\text { lower than that } \\
\text { of a traditional } \\
\text { artificial Hotel, } \\
\text { you will not } \\
\text { doubt its } \\
\text { service quality } \\
\text { and check-in } \\
\text { experience. }\end{array}$ & $\begin{array}{l}\text { service } \\
\text { robot is } \\
\text { very } \\
\text { practical } \\
\text { in hotel. }\end{array}$ & $\begin{array}{l}\text { the service } \\
\text { experience of } \\
\text { the service } \\
\text { robot shown } \\
\text { in the picture } \\
\text { is better than } \\
\text { that of the } \\
\text { manual } \\
\text { service. }\end{array}$ \\
\hline \multirow{3}{*}{$\begin{array}{l}\text { if the price of } \\
\text { hotels using } \\
\text { service robots } \\
\text { is slightly } \\
\text { higher than that } \\
\text { of traditional } \\
\text { artificial hotels, } \\
\text { you will also } \\
\text { choose hotels } \\
\text { using service } \\
\text { robots. }\end{array}$} & $\begin{array}{l}\text { Pearson } \\
\text { Correlation }\end{array}$ & 1 & $.625^{* *}$ & $.710^{* *}$ & $.640^{* *}$ & $.674^{* *}$ & $.639^{* *}$ & $.684^{* *}$ \\
\hline & $\begin{array}{l}\text { Sig. } \\
\text { (2-tailed) }\end{array}$ & & .000 & .000 & .000 & .000 & .000 & .000 \\
\hline & $\mathrm{N}$ & 489 & 489 & 489 & 489 & 489 & 489 & 489 \\
\hline \multirow{3}{*}{$\begin{array}{l}\text { the service } \\
\text { robot shown in } \\
\text { the picture can } \\
\text { meet your } \\
\text { needs. }\end{array}$} & $\begin{array}{l}\text { Pearson } \\
\text { Correlation }\end{array}$ & $.625^{* *}$ & 1 & $.597^{* *}$ & $.687^{* *}$ & $.631^{* *}$ & $.695^{* *}$ & $.674^{* *}$ \\
\hline & $\begin{array}{l}\text { Sig. } \\
\text { (2-tailed) }\end{array}$ & .000 & & .000 & .000 & .000 & .000 & .000 \\
\hline & $\mathrm{N}$ & 489 & 489 & 489 & 489 & 489 & 489 & 489 \\
\hline \multirow{3}{*}{$\begin{array}{l}\text { the service } \\
\text { robot shown in } \\
\text { the picture is } \\
\text { attractive to } \\
\text { you. }\end{array}$} & $\begin{array}{l}\text { Pearson } \\
\text { Correlation }\end{array}$ & $.710^{* *}$ & $.597^{* *}$ & 1 & $.639^{* *}$ & $.707^{* *}$ & $.681^{* *}$ & $.740^{* *}$ \\
\hline & $\begin{array}{l}\text { Sig. } \\
\text { (2-tailed) }\end{array}$ & .000 & .000 & & .000 & .000 & .000 & .000 \\
\hline & $\mathrm{N}$ & 489 & 489 & 489 & 489 & 489 & 489 & 489 \\
\hline \multirow{2}{*}{$\begin{array}{l}\text { the service } \\
\text { robot shown in } \\
\text { the picture can } \\
\text { provide safer }\end{array}$} & $\begin{array}{l}\text { Pearson } \\
\text { Correlation }\end{array}$ & $.640^{* *}$ & $.687^{* *}$ & $.639^{* *}$ & 1 & $.634^{* *}$ & $.726^{* *}$ & $.656^{* *}$ \\
\hline & $\begin{array}{l}\text { Sig. } \\
\text { (2-tailed) }\end{array}$ & .000 & .000 & .000 & & .000 & .000 & .000 \\
\hline
\end{tabular}




\begin{tabular}{|c|c|c|c|c|c|c|c|c|}
\hline $\begin{array}{l}\text { service during } \\
\text { the epidemic } \\
\text { period. }\end{array}$ & $\mathrm{N}$ & 489 & 489 & 489 & 489 & 489 & 489 & 489 \\
\hline \multirow{3}{*}{$\begin{array}{l}\text { if the price of a } \\
\text { hotel using } \\
\text { service robot is } \\
\text { lower than that } \\
\text { of a traditional } \\
\text { artificial Hotel, } \\
\text { you will not } \\
\text { doubt its } \\
\text { service quality } \\
\text { and check-in } \\
\text { experience. }\end{array}$} & $\begin{array}{l}\text { Pearson } \\
\text { Correlation }\end{array}$ & $.674^{* *}$ & $.631^{* *}$ & $.707^{* *}$ & $.634^{* *}$ & 1 & $.640^{* *}$ & $.697^{* *}$ \\
\hline & $\begin{array}{l}\text { Sig. } \\
\text { (2-tailed) }\end{array}$ & .000 & .000 & .000 & .000 & & .000 & .000 \\
\hline & $\mathrm{N}$ & 489 & 489 & 489 & 489 & 489 & 489 & 489 \\
\hline \multirow{3}{*}{$\begin{array}{l}\text { service robot is } \\
\text { very practical } \\
\text { in hotel. }\end{array}$} & $\begin{array}{l}\text { Pearson } \\
\text { Correlation }\end{array}$ & $.639^{* *}$ & $.695^{* *}$ & $.681^{* *}$ & $.726^{* *}$ & $.640^{* *}$ & 1 & $.600^{* *}$ \\
\hline & $\begin{array}{l}\text { Sig. } \\
\text { (2-tailed) }\end{array}$ & .000 & .000 & .000 & .000 & .000 & & .000 \\
\hline & $\mathrm{N}$ & 489 & 489 & 489 & 489 & 489 & 489 & 489 \\
\hline \multirow{3}{*}{$\begin{array}{l}\text { the service } \\
\text { experience of } \\
\text { the service } \\
\text { robot shown in } \\
\text { the picture is } \\
\text { better than that } \\
\text { of the manual } \\
\text { service. }\end{array}$} & $\begin{array}{l}\text { Pearson } \\
\text { Correlation }\end{array}$ & $.684^{* *}$ & $.674^{* *}$ & $.740^{* *}$ & $.656^{* *}$ & $.697^{* *}$ & $.600^{* *}$ & 1 \\
\hline & $\begin{array}{l}\text { Sig. } \\
\text { (2-tailed) }\end{array}$ & .000 & .000 & .000 & .000 & .000 & .000 & \\
\hline & $\mathrm{N}$ & 489 & 489 & 489 & 489 & 489 & 489 & 489 \\
\hline
\end{tabular}

**. Correlation is significant at the 0.01 level (2-tailed).

After seeing the photos of the service process of robots, the respondents can believe that they can provide more valuable services for customers. Under the background of a global epidemic, respondents easily combine the content of the answers with the background of the times. Therefore, the respondents also believe that the service robot can provide more safe services during the epidemic. The numerical fitting degree of the two reaches the highest value of the above-mentioned test value, 0.726 . Here it is confirmed that service robots are considered to provide a safer and more hygienic service in hotels than human service. This factor should be further analysed to confirm whether the impressions attached to the service robots by the effects of the epidemic can directly impact consumer purchase intention.

To further explain the linear correlation between the two, a linear regression equation was established that is supposed to be established again.

$\mathrm{H}_{0}$ : the degree of safe and reliable service provided by the service robot during the epidemic period has nothing to do with the demand satisfaction ability of the service robot

$\mathrm{H}_{1}$ : the degree of safe and reliable service provided by the service robot during the epidemic period is related to the demand satisfaction ability of the service robot 
Table 5.

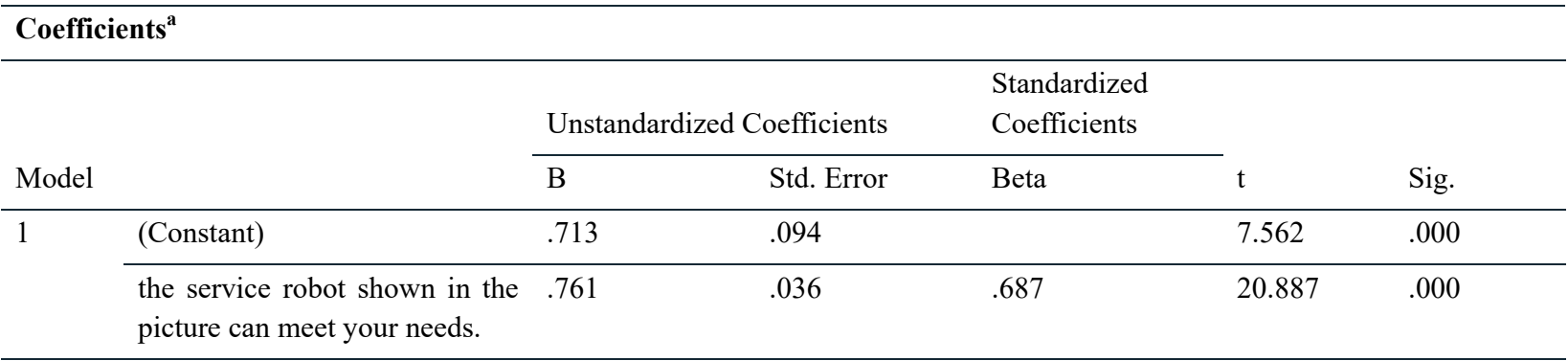

a. Dependent Variable: the service robot shown in the picture can provide safer service during the epidemic period.

The probability of supporting the original hypothesis $(\mathrm{H} 0)$ is less than $1 \%$, so the alternative hypothesis (H1) can be fully accepted. So the linear regression equation can be expressed as

\section{$Y=0.713+0.761 X$}

Therefore, customers can be more sure that the service robot can provide more safe and reliable services during the epidemic period.

This was an essential factor arising from the epidemic and, despite being in a particular market environment, service robots gained a significant influence on consumer purchase intentions as the epidemic changed consumer habits almost permanently. From the above specific analysis and the survey result, there is a positive correlation between consumer purchase intentions and the use of service robots in the Chinese hospitality industry and that the impact of this correlation is likely to persist after the end of the epidemic. This study was not sufficient to fully confirm this continuity effect. However, given the additional impact of the COVID-19 epidemic on service robots and consumer behaviour in the Chinese hospitality industry, the continuing impact of service robots on consumer purchase intentions should be considered to be present.

\section{Indications for Future Research}

The study was conducted almost a year after the COVID-19 outbreak, and the vast majority of those who participated in the survey had experienced the services of a hotel robot, thus making the conjecture that the rollout of robots was rapidly developing as a result of the public health outbreak. Moreover, the resulting crisis communication management in hotels could be further studied. Furthermore, the possibility of substitution in the intersection of the range of robot services and the range of human services, the absence of essential parts in the range of machine services compared to traditional human services, and the impact of specific interaction processes on consumers' willingness to consume are all areas of research based on the derivation of this study. Specifically, this study explores the impact of room service robots and does not examine the other components that make up the hotel service robot ecosystem. Therefore, this study could be used as a basis for research into other parts of the hospitality service robot ecosystem, such as cooking robots or interactive robots, to clarify further the specific patterns of the impact of service robots on customer purchase intentions in the hospitality industry. In addition, this study concluded that an important reason for customers choosing hotels that employ service robots is the impact of the COVID-19 epidemic on human interaction. This finding could be analysed as a separate question for further research to clarify the specific ways in which service robots influence purchase intentions.

This study found that consumers do not consider robot service sufficient to match human service, but the specific service aspects are unknown, and further research could be added to this topic. Furthermore, while a positive correlation can be confirmed between the use of service robots in the Chinese hotel industry and consumer purchase intentions, whether this correlation is continuous has not been verified very concretely. Further investigations could be conducted in the future to determine whether this correlation is continuous. Furthermore, as the data collected in this study was focused on mainland China, the generalisability of the findings in the broader context will need to be further investigated in the future.

It is also important to note that the sample selection was randomized arbitrarily, this is a disadvantage from the perspective of generalisation and future studies should keep this in mind. Hence this can be listed as a limitation of the study. For detailed review of the actual questionnaire can be seen in Appendix A. 


\section{Conclusion}

The three research questions previously posed can be answered here:

First, the adoption of service robots in the Chinese hospitality industry during the COVID-19 pandemic attracted consumers to spend money, and this new model has a higher market appeal than hotels with traditional human service. The factors that can be identified as having the most significant impact on consumer purchase intentions within the scope of this study are the service efficiency of service robots, the human-machine interaction experience, and the lack of need for human contact. The attractiveness of hotels with service robots to potential customers is also significant, and fluctuations in price factors do not diminish the positive effect of service robots on consumer purchase intentions.

Secondly, after the end of the epidemic, it can still be presumed that consumers will prefer to stay in hotels that employ service robots without considering the impact of the human interaction barriers caused by the epidemic. Given the significant impact of the epidemic on consumer behaviour, it can be assumed that consumers will still have a demand for less human contact in the future and that hotels with service robots will be one of the best alternatives to traditional manual hotels.

Thirdly, this analysis shows that existing hotels in China that employ service robots are already popular and can meet the expectations of the majority of customers who stay there. The results are different when comparing customers' expectations of the services provided by current service robots with their expectations of traditional human service. It can be argued that the service process of the service robots provided in this study is not sufficient to meet all of the customer's expectations of hotel services, but it is sufficient to meet the customer's consumption expectations of some of the services presented.

Consumer confidence has been restored in mainland China, and the market in the hotel industry has massive scope for competition in the future due to the COVID-19 outbreak. The large number of community services provided by service robots during the epidemic and the mainstream media coverage has, to some extent, influenced consumer perceptions of service robots and accelerated the rollout of service robots. In the hospitality industry, which requires a high degree of human contact, service robots are gaining even more rapidly. Regardless of whether or not they have experienced the robot service in the hotel, most consumers have positive expectations for the quality of service provided by service robots, so there is significant marketing potential for hotel robots, both now and in the future.

The positive tendency of service robots to promote consumption in the Chinese hospitality industry was identified in this study, and a positive correlation was found between consumer purchase intentions and the use of robots in the Chinese hospitality industry during the COVID-19 outbreak; This correlation is primarily driven by changes in consumer behaviour resulting from the barriers to human interaction created by COVID-19. Also, the community service of service robots during the epidemic had a positive impact on consumers. The analysis of this study supports the conclusion that consumer purchase intentions in the Chinese hospitality industry will continue to be influenced by the use of service robots after the outbreak. On the other hand, the services provided by existing service robots can meet most consumer expectations, but in practice, the service robots still cannot fully deliver a service experience comparable to a human. Also, this study fills a gap in the impact of service robots on the spending intentions of potential hotel customers, confirming that service robots have significant scope for exploration in the Chinese hotel market.

Overall, the COVID-19 epidemic has dramatically increased the speed of rollout and the marketing value of service robots. The adoption of service robots in Chinese hotels can positively impact consumer purchase intentions in the long term. Moreover, the better human-robot collaboration will be a favourable topic for future marketing in the Chinese hospitality industry.

\section{References}

Adami, C. (2015). Robots with instincts. Nature, 521(7553), 426-427. https://doi.org/10.1038/521426a

Advice for the public on COVID-19. Who.int. (2020). Retrieved 27 November 2020, from https://www.who.int/emergencies/diseases/novel-coronavirus-2019/advice-for-public.

Assaf, A., \& Scuderi, R. (2020). COVID-19 and the recovery of the tourism industry. Tourism Economics, 26(5), 731-733. https://doi.org/10.1177/1354816620933712

Bhimasta, R., \& Kuo, P. (2019). What causes the adoption failure of service robots?. Proceedings Of The 2019 ACM International Joint Conference On Pervasive And Ubiquitous Computing And Proceedings Of The 2019 ACM International Symposium On Wearable Computers - Ubicomp/ISWC '19, 1107-1112. 
https://doi.org/10.1145/3341162.3350843

CACM. (2017). Artificial intelligence. Communications of The ACM, 60(2), 10-11. https://doi.org/10.1145/3034429

Chan, A., \& Tung, V. (2019). Examining the effects of robotic service on brand experience: the moderating role of hotel segment. Journal Of Travel \& Tourism Marketing, 36(4), 458-468. https://doi.org/10.1080/10548408.2019.1568953

Chen, X., Zhang, X., Song, X., Fu, L., \& Liu, M. (2020). 2020 China Restaurant Industry Survey Report (pp. 30-36, 44-48). Beijing: China Hospitality Association. Retrieved from https://baogaocos.seedsufe.com/2020/10/22/tmp_1603364734595000.pdf

China Hospitality Association. (2020). 新冠疫情下3 月中国住宿业生存现状报告 (COVID-19 Survival Status Report for China's Accommodation Industry in March) . Chinahotel.org.cn. Retrieved 5 November 2020, from http://www.chinahotel.org.cn/forward/enterenterSecondDaryOther.do? contentId=120786f519974afea65a337602 4dddf6.

Choi, Y., Choi, M., Oh, M., \& Kim, S. (2019). Service robots in hotels: understanding the service quality perceptions of human-robot interaction. Journal of Hospitality Marketing \& Management, 29(6), 613-635. https://doi.org/10.1080/19368623.2020.1703871

Dehghani, M., \& Tumer, M. (2015). A research on effectiveness of Facebook advertising on enhancing purchase intention of consumers. Computers In Human Behavior, 49, 597-600. https://doi.org/10.1016/j.chb.2015.03.051

Goertzel, B. (2015). Artificial General Intelligence. Scholarpedia, 10(11), 31847. https://doi.org/10.4249/scholarpedia.31847

Goertzel, T. (2014). The path to more general artificial intelligence. Journal Of Experimental \& Theoretical Artificial Intelligence, 26(3), 343-354. https://doi.org/10.1080/0952813x.2014.895106

Hao, F., Xiao, Q., \& Chon, K. (2020). COVID-19 and China's Hotel Industry: Impacts, a Disaster Management Framework, and Post-Pandemic Agenda. International Journal Of Hospitality Management, 90, 102636. https://doi.org/10.1016/j.ijhm.2020.102636

Hoque, A., Shikha, F., Hasanat, M., \& Arif, I. (2020). The Effect of Corona virus (COVID - 19) in the Tourism Industry in China. Asian Journal Of Multidisciplinary Studies, 3(1), 52-58. Retrieved 14 November 2020, from.

Huang, M., \& Rust, R. (2018). Artificial Intelligence in Service. Journal Of Service Research, 21(2), 155-172. https://doi.org/10.1177/1094670517752459

Ivanov, S., \& Webster, C. (2019). Perceived Appropriateness and Intention to Use Service Robots in Tourism. Information And Communication Technologies In Tourism 2019, 237-248. https://doi.org/10.1007/978-3-030-05940-8_19

Ivanov, S., Webster, C., Stoilova, E., \& Slobodskoy, D. (2020). Biosecurity, crisis management, automation technologies and economic performance of travel, tourism and hospitality companies - A conceptual framework. Tourism Economics. https://doi.org/10.1177/1354816620946541

Jiang, Y., \& Wen, J. (2020). Effects of COVID-19 on hotel marketing and management: a perspective article. International Journal of Contemporary Hospitality Management, 32(8), 2563-2573. https://doi.org/10.1108/ijchm-03-2020-0237

Klotz, F. (2018). How AI Can Amplify Human Competencies. MIT Sloan Management Review, 60(1), 14-15. $\begin{array}{llll}\text { Retrieved } & 20 & \text { November } & 2020,\end{array}$ https://login.ezproxy.cbu.ca/login?url=https://www-proquest-com.ezproxy.cbu.ca/docview/2112535491?account $\mathrm{id}=9874$.

Leung, X., Tanford, S., \& Jiang, L. (2017). Is a picture really worth a thousand words?. Journal Of Hospitality And Tourism Technology, 8(1), 19-38. https://doi.org/10.1108/jhtt-08-2016-0039

Li, G. (2020). Qunar.com "epidemic radar". Financialnews.com.cn. Retrieved 1 December 2020, from https://www.financialnews.com.cn/cj/sc/202003/t20200302_182410.html.

Li, Y., Fu, H., \& Huang, S. (2015). Does conspicuous decoration style influence customer's intention to purchase? The moderating effect of CSR practices. International Journal Of Hospitality Management, 51, 19-29. https://doi.org/10.1016/j.ijhm.2015.08.008

Lisetti, C., \& Schiano, D. (2000). Automatic facial expression interpretation. Facial Information Processing, 8(1), 
185-235. https://doi.org/10.1075/pc.8.1.09lis

Meisenzahl, M. (2020). How Asia, the US, and Europe are using robots to replace and help humans fight coronavirus by delivering groceries, sanitizing hospitals, and monitoring patients. Business Insider. Retrieved 17 November 2020, from https://www.businessinsider.com/robots-fighting-coronavirus-in-china-us-andeurope-2020-3

Mi, S. (2020). Robotic “big data” in the hospitality industry's “power of prevention and control “云迹科技: 机器 人 “大数据”中的酒店业 “防控力”. Xfrb.com.cn. Retrieved 3 January 2021, from http://www.xfrb.com.cn/article/stjj-pptg/13252431786423.html.

Pandey, A., \& Gelin, R. (2018). A Mass-Produced Sociable Humanoid Robot: Pepper: The First Machine of Its Kind. IEEE Robotics \& Automation Magazine, 25(3), 40-48. https://doi.org/10.1109/mra.2018.2833157

Patrick, B. (2020). What is artificial intelligence?. Journal Of Accountancy, 229(2), 69. Retrieved 19 November 2020, from https://ink.gale.com/apps/doc/A613922718/AONE?u=capebret\&sid=AONE\&xid=34326155.

Reis, J., Melão, N., Salvadorinho, J., Soares, B., \& Rosete, A. (2020). Service robots in the hospitality industry: The case of Henn-na hotel, Japan. Technology In Society, 63, 101423. https://doi.org/10.1016/j.techsoc.2020.101423

Rodriguez-Lizundia, E., Marcos, S., Zalama, E., Gómez-García-Bermejo, J., \& Gordaliza, A. (2015). A bellboy robot: Study of the effects of robot behaviour on user engagement and comfort. International Journal of Human-Computer Studies, 82, 83-95. https://doi.org/10.1016/j.ijhcs.2015.06.001

Ruetz, D. (2016). Robots in hotels will work with humans, not replace them | PhocusWire. Phocuswire.com. $\begin{array}{llll}\text { Retrieved } & 17 & \text { November } & 2020,\end{array}$ https://www.phocuswire.com/Robots-in-hotels-will-work-with-humans-not-replace-them.

Sample Size and Margin of Error. PennState: Statistics Online Courses. (2021). Retrieved 6 January 2021, from https://online.stat.psu.edu/stat100/lesson/2/2.3.

Shang, S., Wu, Y., \& Sie, Y. (2017). Generating consumer resonance for purchase intention on social network sites. Computers In Human Behavior, 69, 18-28. https://doi.org/10.1016/j.chb.2016.12.014

Tsao, W., Hsieh, M., Shih, L., \& Lin, T. (2015). Compliance with eWOM: The influence of hotel reviews on booking intention from the perspective of consumer conformity. International Journal of Hospitality Management, 46, 99-111. https://doi.org/10.1016/j.ijhm.2015.01.008

Tung, V., \& Au, N. (2018). Exploring customer experiences with robotics in hospitality. International Journal Of Contemporary Hospitality Management, 30(7), 2680-2697. https://doi.org/10.1108/ijchm-06-2017-0322

Tussyadiah, I. (2020). A review of research into automation in tourism: Launching the Annals of Tourism Research Curated Collection on Artificial Intelligence and Robotics in Tourism. Annals of Tourism Research, 81. https://doi.org/10.1016/j.annals.2020.102883

WHO COVID-19. Covid19.who.int. (2020). Retrieved 27 November 2020, from https://covid19.who.int/.

Xia, Y., \& Jun, S. (2020). SARS 的经济影响以及对新型冠状病毒疫情经济影响的启示(The Economic impacts of SARS and Economic Implications for the Novel Coronavirus Outbreak in China). Shanghai Economy, 3, 7-15. Retrieved 28 November 2020, from.

Yang, G., J. Nelson, B., Murphy, R., Choset, H., Christensen, H., \& H. Collins, S. et al. (2020). Combating COVID-19-The role of robotics in managing public health and infectious diseases. Science Robotics, 5(40), eabb5589. https://doi.org/10.1126/scirobotics.abb5589

Yao, F., Zhang, C., \& Chen, W. (2015). Smart talking robot Xiaotu: participatory library service based on artificial intelligence. Library Hi Tech, 33(2), 245-260. https://doi.org/10.1108/lht-02-2015-0010

Zeng, Z., Chen, P., \& Lew, A. (2020). From high-touch to high-tech: COVID-19 drives robotics adoption. Tourism Geographies, 22(3), 724-734. https://doi.org/10.1080/14616688.2020.1762118

Zhong, L., Sun, S., Law, R., \& Zhang, X. (2020). Impact of robot hotel service on consumers' purchase intention: a control experiment. Asia Pacific Journal of Tourism Research, 25(7), 780-798. https://doi.org/10.1080/10941665.2020.1726421 


\section{Appendix A}

\section{Survey Questionnaire}

Hello! I am an MBA student at Cape Breton University, doing academic research. The purpose of the questionnaire is to investigate the marketing potential for using service robots in the hospitality industry in China under today's market situation.

\section{INFORMED CONSENT}

\section{Research Purpose}

\section{Researcher}

Dr. Ayse Ersoy ayse_ersoy@cbu.ca and

\section{Research Description}

\section{Informed Consent}

I have been informed of the purpose of this research and agree to participate in this survey.

If you have any questions that have not been answered satisfactorily by the researcher(s) named above please contact:

Co-chair of the Research Ethics Board at CBU, Sandra Jack-Malik, email: Sandra_Jack-Malik@cbu.ca Co-chair of the Research Ethics Board at CBU, Dr. Erna MacLeod, Co-Chair of the REB at erna_macleod@cbu.ca Administrator, Nicole MacDougall at(902) 563-1107, email: ethics@cbu.ca

Note: Participants are to be informed of the researcher(s)' "Duty to disclose" suspected abuse or neglect of a child or an adult in need of protection. Under section 23(1), Nova Scotia Children and their Family, The Protection of Children and Adoption (1990) states that "Every person who has information, whether it is confidential or privileged, indicating that a child is in need of protective services shall forthwith report that information to an agency." Agency is defined as "an agency continued by or established and incorporated pursuant to the act..." that is, Nova Scotia Department of Community Service Child Welfare. This may vary across provinces within Canada and different regions outside of Canada. 


\section{Screening Questions}

1. Did you stay in hotels regularly before the outbreak of the COVID-19?
Yes
No

2. Are you planning to stay at a hotel in the future?

Yes

No

3. Have you ever stayed in a hotel with a robot waiter?

If you answer no to any of the first three questions, you do not need to answer the rest of the survey. Thank you for your time and kind consideration.

If your answers are yes, please circle only one answer that describes your situation the best in the following questions.

1. Are you satisfied with the service experience of the robot? (Those who have experienced)

a. Yes

b. No

\begin{tabular}{|l|l|l|l|l|l|}
\hline & $\begin{array}{l}\text { Strongly } \\
\text { Agree }\end{array}$ & Agree & Neutral & Disagree & Strongly Disagree \\
\hline $\begin{array}{l}\text { The robot's service is quick } \\
\text { and easy }\end{array}$ & & & & \\
\hline $\begin{array}{l}\text { 1. The interaction with the } \\
\text { robots is innovative and } \\
\text { interesting. }\end{array}$ & & & & \\
\hline $\begin{array}{l}\text { 2. The service quality of } \\
\text { service robots is superior or } \\
\text { not inferior to that of service } \\
\text { staff. }\end{array}$ & & & & & \\
\hline $\begin{array}{l}\text { Service robots provide a } \\
\text { more high-end service } \\
\text { experience than manual } \\
\text { service }\end{array}$ & & & & & \\
\hline $\begin{array}{l}\text { 3. Compared to hotels with } \\
\text { traditional manual service, } \\
\text { the prices charged by hotels } \\
\text { with robotic service are } \\
\text { reasonable. }\end{array}$ & & & & & \\
\hline $\begin{array}{l}\text { 4. The robot's service in hotel } \\
\text { is not convenient or stable } \\
\text { enough. }\end{array}$ & & & & \\
\hline
\end{tabular}




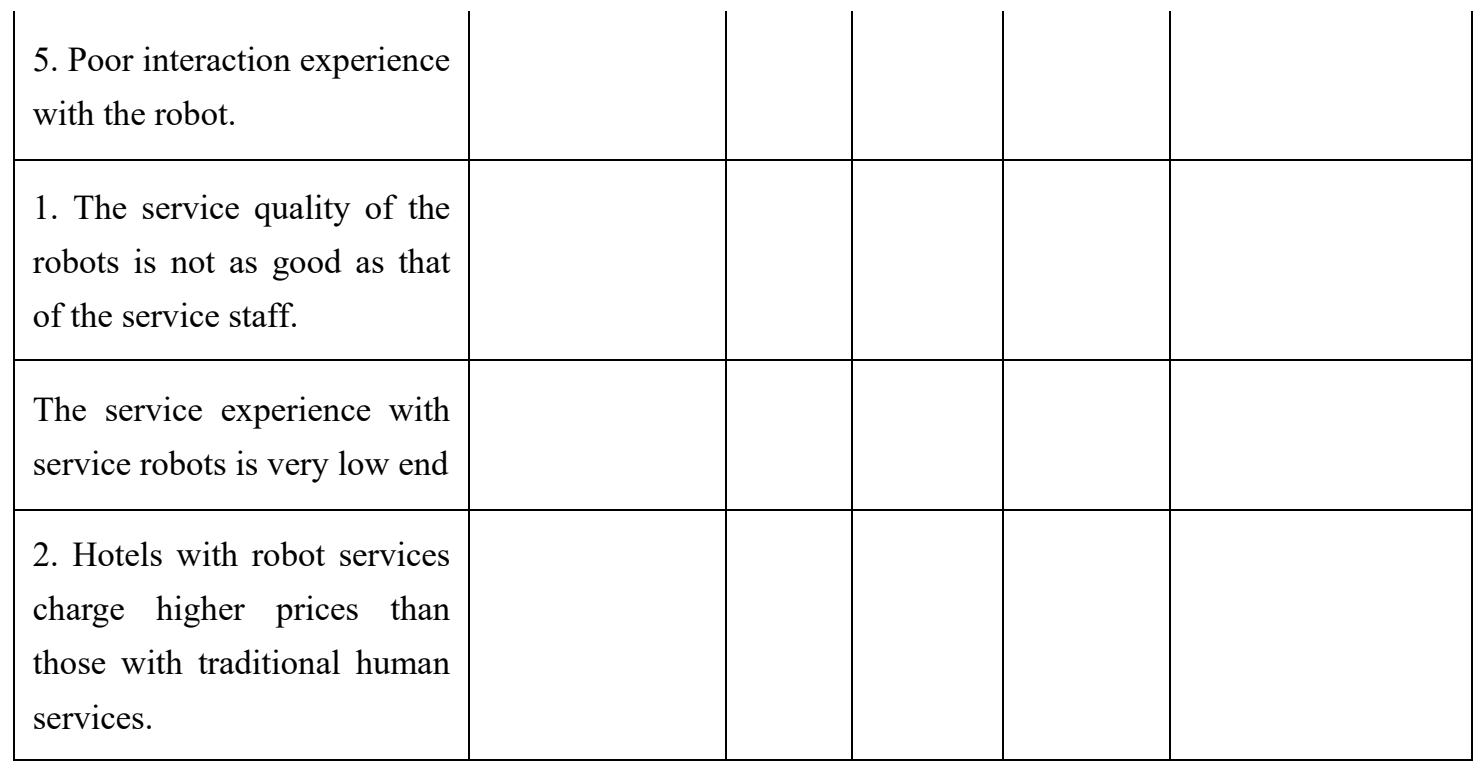

1) What are your impressions of service robots? (For those who have not experienced)

Positive (Answer question a-d)

Negative (Answer question A-D)

2) The robot's service is quick and easy.

Strongly agree Agree Neither agree nor disagree Disagree Strongly disagree

3) The interaction with the robots is innovative and interesting.

Strongly agree Agree Neither agree nor disagree Disagree Strongly disagree

4) The service quality of service robots is superior or not inferior to that of service staff.

Strongly agree Agree Neither agree nor disagree Disagree Strongly disagree

5) Service robots provide a more high-end service experience than manual service.

$$
\text { Strongly agree Agree Neither agree nor disagree Disagree Strongly disagree }
$$

6) Compared to hotels with traditional manual service, the prices charged by hotels with robotic service are reasonable.

$$
\text { Strongly agree Agree Neither agree nor disagree Disagree Strongly disagree }
$$

7) The robot's service in hotel is not convenient or stable enough.

Strongly agree Agree Neither agree nor disagree Disagree Strongly disagree 
8) Poor interaction experience with the robot.

$$
\text { Strongly agree Agree Neither agree nor disagree Disagree Strongly disagree }
$$

9) The service quality of the robots is not as good as that of the service staff.

$$
\text { Strongly agree Agree Neither agree nor disagree Disagree Strongly disagree }
$$

10) The service experience with service robots is very low end.

$$
\text { Strongly agree Agree Neither agree nor disagree Disagree Strongly disagree }
$$

11) Hotels with robot services charge higher prices than those with traditional human services.

$$
\text { Strongly agree Agree Neither agree nor disagree Disagree Strongly disagree }
$$

12) Would you choose to stay in a hotel with a service robot for your future trips if price was not a consideration?

$$
\text { Yes } \quad \text { No }
$$

13) What do you think of the claim that service robots effectively reduce human contact and reduce the risk of disease transmission?

$$
\text { Strongly agree Agree Neither agree nor disagree Disagree Strongly disagree }
$$

14) Do you think a service robot can meet most of your needs during your stay in a hotel?

$$
\text { Strongly agree Agree Neither agree nor disagree Disagree Strongly disagree }
$$

15) Would you prefer a hotel with a service robot to one that is fully staffed, regardless of price?

$$
\text { Strongly agree Agree Neither agree nor disagree Disagree Strongly disagree }
$$

\section{Part Two}

Please watch the information about the service robot's service process in the hotel and continue to complete the questionnaire afterwards.

\section{(Video and photo material)}

After viewing the material, and without considering the price, would you choose to stay in a hotel that uses service robots for your future travels?

$$
\text { Yes No }
$$

(If the answer is Yes)

You would still choose a hotel with a service robot if the hotel's price with the service robot were slightly higher than that of a hotel with traditional human service.

$$
\text { Strongly agree Agree Neither agree nor disagree Disagree Strongly disagree }
$$


a) The service quality of the service robots shown in the material will meet most of your needs.
Strongly agree
Agree Neither agree nor disagree
Disagree Strongly disagree

b) The service experience of the service robot shown in the material is very attractive.
Strongly agree
Agree Neither agree nor disagree
Disagree Strongly disagree

c) The service robots shown in the material can bring safer service during disease epidemics.
Strongly agree
Agree Neither agree nor disagree
Disagree Strongly disagree

Suppose the price of a hotel with a service robot is lower than a traditional human hotel. In that case, you may have doubts about the quality of service and the experience of staying in such hotels.

$$
\text { Strongly agree Agree Neither agree nor disagree Disagree Strongly disagree }
$$

(If the answer is No)

The use of service robots in hotels is not practical and is more of a commercial gimmick.
Strongly agree
Agree Neither agree nor disagree
Disagree Strongly disagree

a) The service quality of the service robots shown in the material does not meet your needs.

Strongly agree Agree Neither agree nor disagree Disagree Strongly disagree

b) The service experience of the service robots shown in the material is not as good as that of human service.
Strongly agree
Agree Neither agree nor disagree
Disagree Strongly disagree

c) The service robots shown in the material can bring safer service during disease epidemics.

Strongly agree Agree Neither agree nor disagree Disagree Strongly disagree

\section{This questionnaire has been completed, thank you for your participation!}

\section{Copyrights}

Copyright for this article is retained by the author(s), with first publication rights granted to the journal.

This is an open-access article distributed under the terms and conditions of the Creative Commons Attribution license (http://creativecommons.org/licenses/by/4.0/). 